\title{
Exploring Local Cultural Perspectives in User Interface Development in an Indian Offshoring Context: A View from the UK
}

\author{
Malte Ressin ${ }^{1}$, Cecilia Oyugi ${ }^{1}$, José Abdelnour-Nocera ${ }^{1}$, David Lee ${ }^{2}$, \\ and Dharam Panesar ${ }^{1}$ \\ ${ }^{1}$ University of West London, Centre for Usability and Internationalisation \\ W5 5RF London, United Kingdom \\ \{malte.ressin, cecilia.oyugi, jose.abdelnour-nocera, \\ dharam.panesar\}@uwl .ac.uk \\ ${ }^{2}$ VocaLink \\ EC2V 7BB London, United Kingdom \\ david.lee@vocalink.com
}

\begin{abstract}
In this paper, we present the results of an exploratory case study on the impact of culture on software development in an offshoring context in India. Our research aims to understand the role of culture in outsourced software development. We interviewed human-computer interface professionals such as frontend developers, user interface designers and usability specialists working for a software development outsourcing vendor in India. The interviews were analysed for occurrence of common themes. Thereafter the cultural models of Hofstede and Hall were used to make sense of these emerging themes.. Our results indicate that cultural influence occurs and has an overarching influence in software development. Three proposals are made in response to the cultural issues highlighted.
\end{abstract}

Keywords: offshoring, outsourcing, culture, software development.

\section{Introduction}

Offshoring has been an attractive option for some western countries mainly due to the lower costs involved. PricewaterhouseCoopers carried out a research establishing that $79 \%$ of the companies in western countries indicated that lower transactional costs were their main reason for offshoring [1]. Other important reasons that have driven the developed nations to offshore include the shortage of skilled workers and the continued improvement of the global transport and communication network. Initially, the IT industry started by offshoring services that are low cost, such as IT help desk call centres. However, development in offshoring has seen the IT sector expand to offshore complex high-end skills and knowledge work activities such as software development. It is predicted that this type of activity will continue to grow. For instance, NASSCOM predict Indian IT business process outsourcing revenues of USD225 billion by 2020 [2]. Since cost is a central consideration while making a decision to offshoring, it is possible that other issues such as cultural differences 
between the offshoring client and the offshoring vendor are easily overlooked. Cultural differences have the potential to affect not only the software development process but also the product itself (for example in the cases where localisation is involved).

The study of how culture relates to ICT development is a growing discipline in the Human Computer Interaction (HCI) community. However, most of the current work in this area has been on how culture affects the user interaction with the end product (e.g. [3], [4] and [5]). The focus of this paper is the importance of cultural implications for offshoring which have not been extensively researched. This report is a follow-up of a larger research where an on-line questionnaire was implemented to investigate the effects of culture on the quality of software in an offshoring context [6]. The web based survey attracted 436 responses representing 44 declared nationalities. The regional / country groups represented were West (UK, US and Australia), Eastern Europe (Hungary, Moldova and Romania) and Asia (India, Bangladesh and China). The data analysis of the online questionnaire suggested that there is a significant difference in attitudes occurring between the western clients and the offshoring vendors. Consequently, this can lead to misunderstandings between the two players which can in turn manifest in terms of poorly developed software.

\section{Cultural Considerations within Offshoring}

Culture is a difficult and elusive concept to define partly because of the pluralistic interest that it has gained from various academic disciplines with each of them having its own focus [7]. As a result of the varied understandings of the concept of culture, authors such as Honold propose that researchers should select the definition of culture that best suits their context [8]. Therefore, the definition that will best suit the scope of this research is the one based on shared value patterns across individuals and within groups. Specifically, Hofstede's definition of culture will be adopted during this investigation: "Culture is the collective programming of the mind which distinguishes the members of one group or category of people from another" ([9], p. 9). This computer programming parallel implies that all people have comparable brains and refers to culture as the 'software of the mind'. This means that the patterns of thinking, feeling and acting are as a result of culture which acts like 'mental programs'. Further, these 'mental programs' become part of people's lives during their interactions with the environment when growing up.

In order to better understand customs and practices in a target culture, researchers have used the concept of cultural models. These models are based on the assumption that cultural differences are a result of social learning through interaction with the environment which has taken place for long periods of time. Two of these models, Hofstede's [9] and Hall's [10], will be considered in this study.

Hofstede [9] proposes that culture varies along relationships with people (individualism vs. collectivism), the extent to which a culture embraces social inequality (power distance), the extent to which members of a culture tend to stay 
away from uncertain situations (uncertainty avoidance), the degree to which people prefer values of success and competition over modesty and concern for others (masculinity vs. femininity), and finally their relationship to time horizon (long term vs. short term orientation).

In his cultural model, Hall [10] proposes that a culture is either high or low context, is monochronic or polychronic in its orientation to time, decodes and acts on messages slowly or quickly and has differences in its sense of space dimensions.

The cultural dimensions proposed by Hofstede have been extended and applied in offshoring for example by [11]. However, the extent to which these theoretical cultural dimensions continue to be relevant and extendable has been questioned (e.g. [12], [13], [14] and [15]). Nonetheless, Hofstede has aptly responded to some of this criticism and his work remains highly influential in the area of cross-cultural research [16]. This paper will therefore use the theoretical underpinning of the cultural models of Hofstede [9] and Hall [10] to understand how cultural differences can and do impinge on global software development.

\section{Methodology}

To gather data for the study, we got an opportunity to conduct interviews with employees of an Indian offshoring software development company. As contact to our host companies prior to our field work was informal, we decided to use semistructured interviews for our data gathering to account for the unknown range of access we would have on location. We therefore developed a solid interview script which would allow us to explore the subject area (cultural influences on the development process in offshoring projects), yet retain flexibility in branching out into the specialist areas of knowledge of our unknown interview partners.

The interview script was developed iteratively, taking as a starting point the survey questions from [6]. The interviews started off by asking the interviewees about their exact role, work experience and education. They then continued with questions about the interviewee's perceptions of quality in software, both absolutely and in relation to schedule and budget constraints, as well as in relation to client's and the host company's interests. Further topics discussed in the interviews included requirements gathering, specifications and documentation, the working relationship to clients and the employed development methodologies.

In some questions, we asked interviewees for their opinions and judgement. For example, question 14 was:

Consider the three targets Schedule, Budget and Quality. Which one is the most important for you personally? In your opinion, which one does your employer (the offshoring vendor) value most? Which one do your clients value most?

We also allowed interviewees to simply relate to previous experiences. For example, questions 5 and 6 were: 
Tell me about the most successful outsourcing project that you were part of. How did you know it was successful? What do you think were the reasons for its success?

Tell me about an outsourcing project you were part of that did not go well. What were the major problems? What do you think caused the problems? How could the problems have been corrected or avoided? If that didn't happen, why do you think it didn't happen?

Last but not least, we gave interviewees the opportunity to hypothesize. For example, question 16 was:

If you could change anything in the way your software is developed, what would that be and why?

Depending on the answers, additional questions were inserted at the interviewer's discretion to deepen or clarify a point, etc.

Our host company has more than 10.000 employees working on outsourcing services across the whole range of software development services. Development is mostly done in several locations in India, but subsidiaries in several overseas countries exist. Fifteen interviews were conducted over six work days at two of our host company's sites in Mumbai and Pune. They took between 35 and 55 minutes (average 43:16). Interviewees worked on user interface development for website and software development offshoring projects in the roles of frontend developer (5), user experience specialist (8), and project manager (2).

In addition, one additional interview with a user experience specialist and a group session with ca. 30 HCI professionals at another offshoring company in Pune. This second company also offers offshoring for software development projects with development centres in several locations in India and additional offices overseas.

\section{$4 \quad$ Data Analysis and Results}

To analyse the data, the researcher who collected the data from India and one other independent researcher listened to the audio recordings of the interviews independently. The goal of this exercise was for each researcher to independently hand-pick important themes from the interviews and then compare the recurring themes between the two researchers. This structure was used to mitigate for individual bias and increase reliability. Therefore, the interviews were examined for common or contradictory themes indicated in the answers of the interviewees. Behaviour and implications as interpreted by us were also considered. The discovered themes were compared with cultural models of Hofstede and Hall, and pre-existing categories derived from previous cultural research were also underpinning the higher-level analysis. To mitigate for individual bias and increase reliability, analysis was conducted independently and in a parallel fashion by two of the authors. After comparing notes, the authors used their agreed results to create a 
number of conjectures how cultural differences manifest themselves in offshoring development.

Following is a highlight of the most important but expected cultural dependencies from the interview analysis. For example, interviewees regularly deferred questions on their own views or opinions to the authority of their superiors and loyalty to their company. In another example, many interviewees went out of their way to avoid statements which could be interpreted as criticizing others. When asked about it, they elaborated that criticism on the work of others were demeaning and therefore ethically questionable.

Most interviewees had BSc or MSc degrees in a software engineering discipline and had changed into HCI or a usability-related job role at a later date. Often, this change had been motivated by personal interest. However, almost no interviewee had received formal education in the HCI field. As far as their knowledge around HCI and usability was concerned, they were essentially self-taught. This is hardly surprising since HCI as a discipline is comparatively young and at the time many of today's professionals were studying, the number of HCI-related studies on offer was more limited than today.

During our interviews, the criteria comprising quality in software products was strongly influenced by the role of the interviewee. Those in an engineering role, e.g. frontend developer, considered quality in code-related terms like absence of bugs or fast execution speed/short application reaction time. Interviewees in a role related to classical usability, e.g. usability specialist, considered quality in terms of user-related terms like intuitive use and easy learnability. This is not particularly surprising: admittedly, an individual's role and its associated aims influence the perception of quality, and respective criteria must be informed by one's own discipline. Otherwise, a confounding impact on project and work aims would follow. However, the strong apparent dependence on role is surprising insofar as, as previously discussed, most interviewees have a code-related background and can be expected to have a certain knowledge in associated technical quality criteria. In that light, we would have expected code-related quality criteria to feature in each interviewee's answer to at least some extent. It is also noteworthy that at least to some extent, quality goals seem to be handled on an individual basis and no project- or company-overarching mantra or guideline was mentioned.

The actual development methodologies used at the host company in the user interface development were difficult to determine. Interviewees' statements did not always align in that regard. Some interviewees identified the development methodologies as linear or even categorized it specifically as Waterfall model. Other interviewees on the same project or even the same team described the development methodologies as agile. Unfortunately, as we did not consult additional documentation, we cannot be sure what methodology is or was actually in use in the respective projects.

A number of interviewees mentioned that they found Western clients easier to deal with than Indian clients because of the explicit nature of the work assignment. Interviewees stated that Western clients usually have a very clear idea what they want and communicate their expectations, often in relation to their budget. Indian clients on 
the other hand, on top of usually having stricter budget limitations, seem to keep project scopes more flexible and negotiate it together with the vendor, often in conjunction with project costs.

\section{Discussion}

We found clear indications supporting Hofstede's views on authoritative hierarchy, and reluctance to criticize in collectivist cultures. In addition to that, we came up with a number of conjectures relating our observations with Hall's cultural dimensions, in particular High Context vs. Low Context, and India being a high-context culture:

- Quality criteria are not necessarily elaborated explicitly. Instead, it is left in the interpretation of each individual on the project.

- Work processes are not explicitly specified or described. Individuals instead find their role and their work processes through interpretation.

- Qualification is considered less dependent on formal education, and is instead seen in personal interest and effort.

- Implicitness, possibly in combination with local negotiation customs, conflicts with the explicitness in software development, in particular writing code.

Summarized and re-phrased, the general relative nature of high-context cultures means that virtually everything can be subject to vagueness and/or post-hoc interpretation. This does not stop in software development.

There is evidence to certain collectivist traits as well. Further, at a lower level of practice, there seems to be evidence that IT professionals are converging culturally in certain attitudes to quality and management [17].

Consequently we propose three points of action as a result of this exploratory investigation. First, the issue of quality of software needs to explicitly be defined at the start of the project especially from the western client's perspective. Second, the methodologies used during the software development process as well as code documentation need to clearly be addressed at the start of the project. Third, in-house training could be encouraged to standardize the software development process because of the lack of formal qualification among the software vendors.

\section{Conclusion}

We believe that these conjectures provide an interesting insight into the offshoring vendor context. Unfortunately, we have to acknowledge limitations to the scope of our study. The number of individuals interviewed, as well as the fact that almost all of them worked for the same company and exhibited similar career paths, impacts the applicability on the larger group of HCI professionals.

In future research, our data and results might be put in comparison, for example by comparing HCI professionals from India to HCI professionals from other countries, 
particularly those with low-context cultures. Quantitative data gathering and statistical analysis should be employed to test those conjectures which can be operationalised, e.g. the correlation between quality criteria and role despite constant education/background. Future qualitative data could include formal project documentation where available. Focus groups could discuss items which were ambiguous in the interviews, for example regarding the contradicting statements about development methodologies.

There is a certain amount of criticism in the researcher community to the general concept of trying to "measure" culture along dimensions [18], or to apply such classifications to software development [19]. We believe that a comparison with Hofstede is legitimate, though, since both his and our participants are technologists.

Offshoring will remain an important aspect of software development. The dependency between client and vendor cultures continue to be in the spotlight, especially considering that it is not inconceivable any more that the direction outsourcing has been taking in the past, from West to East, might eventually reverse.

\section{References}

1. PriceWaterhouseCoopers: Offshoring Set to Double in the Financial Services Sector by 2008 (2005), http://www . pwc.com/in/en/press-releases/offshoringfinancial-services . jhtml (accessed May 28, 2012)

2. NASSCOM: IT-BPO Sector in India: Strategic Review 2010, Executive Summary (2010)

3. Yeo, A.: Global Software Development Lifecycle: An Exploratory Study. In: Jacko, J., Sears, A., Beaudouin-Lafon, M., Jacob, R. (eds.) CHI 2001: Conference on Human Factors in Computing Systems, p. 104. ACM Press (2001)

4. Vatrapu, R., Pérez-Quiñones, M.: Culture and Usability Evaluation: The Effects of Culture in Structured Interviews. Journal of Usability Studies 1(4), 156-170 (2006)

5. Oyugi, C., Dunckley, L., Smith, A.: Evaluation methods and cultural differences: studies across three continents. In: Proceedings of the 5th Nordic Conference on HumanComputer Interaction: Building Bridges, Lund, Sweden. ACM International Conference Proceeding Series, vol. 358, pp. 318-325 (2008)

6. Lee, D.: An investigation into the relationship between quality, national culture and cost in offshore software development. PhD thesis, University of West London (2008)

7. Williams, R.: Keywords: A Vocabulary of Culture and Society. Oxford University Press, New York (1983)

8. Honold, P.: Culture and Context: An Empirical Study for the development of a Framework for the Elicitation of Cultural Influence in Product Usage. International Journal of HumanComputer Interaction 12(3\&4), 327-345 (2000)

9. Hofstede, G.: Culture's consequences: Comparing values, behaviors, institutions, and organizations across nations, 2nd edn. (2001)

10. Hall, E.T.: Beyond Culture. Doubleday, Garden City (1976)

11. Carmel, E., Tjia, P.: Offshoring information technology: sourcing and outsourcing to a global workforce. Cambridge University Press, Cambridge (2005)

12. McSweeney, B.: Hofstede's Model of National Cultural Differences and their Consequences: A triumph of faith - A failure of analysis. Human Relations 55(1), 89-118 (2002) 
13. Baskerville, R.F.: Hofstede Never Studied Culture. Accounting, Organizations and Society 28, 1-14 (2003)

14. Ratner, C., Hui, L.: Theoretical and Methodological Problems in Cross-Cultural Psychology. Journal for the Theory of Social Behavior 33, 67-94 (2003)

15. Kruger, T., Roodt, G.: Hofstede's VSM-94 Revisited: Is it reliable and valid? SA Journal of Industrial Psychology 29(1), 75-85 (2003)

16. Hofstede, G.: Dimensions Do Not Exist - A Reply to Brendan McSweeney. Human Relations 55(11) (2002)

17. Lee, D., Smith, A., Mortimer, M.: Cultural differences affecting quality and productivity in Western/Asian offshore software development. In: Proceedings of India HCI 2011 (2011)

18. Hall, P.: The Cross-Cultural Web. In: Day, D.L., Dunckley, L.M. (eds.) Designing for Global Markets 3 (IWIPS 2001), pp. 109-113 (2001)

19. Abufardeh, S., Magel, K.: The Impact of Global Software Cultural and Linguistic Aspects on Global Sofware Development Process (GSD): Issues and Challenges. In: Proceedings of the 4th International Conference on New Trends in Information Science and Service Science, pp. 133-138 (2010) 